\title{
Desafios, estratégias e alianças das centrais sindicais no Mercosul
}

\author{
Alan Barbiero e Yves Chaloult
}

\section{Introdução}

Ao longo dos anos 1990, o processo de regionalização e consolidação de blocos econômicos foi se intensificando e despertando o interesse em diferentes atores sociais. O Mercado Comum do Sul (Mercosul) tornou-se um importante tema na agenda sindical. Inicialmente, a integração regional chamou pouca atenção da maior parte das centrais sindicais do Cone Sul. Todavia, à medida que os governos do Brasil, Argentina, Uruguai e Paraguai aprofundavam as negociações, essas organizações iam transformando sua estratégia de inserção nesse processo. As centrais passaram a reivindicar maiores espaços de participação, bem como a inclusão da "dimensão social" nos acordos de âmbito regional.

Entretanto, o Mercosul criou uma nova situação para as centrais, que permitiu o desenvolvimento de um certo tipo de agregabilidade entre as mesmas. Apesar de

${ }^{1}$ Alan Barbiero é professor do Departamento de Economia da Universidade do Tocantins (Unitins) e doutorando em Sociologia pelo Centro de Pesquisa e Pós-Graduação sobre a América Latina e Caribe (Ceppac) da Universidade de Brasília (UnB). E-Mail alan@unb.br

Yves Chaloult, doutor em Sociologia do Desenvolvimento pela Universidade de Cornell, EUA, é professor do Departamento de Sociologia da UnB. E-Mail yves@unb.br. Este trabalho é um dos resultados do Projeto Integrado de Pesquisa "Mercosul, Nafta e Alca: Transnacionalização das Práticas Sindicais", coordenado pelos Professores Yves Chaloult (UnB) e Dorval Brunelle (Université du Québec à Montréal -Uqam), e financiado pelo Conselho Nacional de Desenvolvimento Científico e Tecnologíco (CNPq). 
haver diferenças históricas, ideológicas e mesmo político-partidárias entre as centrais do Cone Sul, elas construíram - e ainda estão construindo - uma posição comum no que se refere ao tema da regionalização. Novos espaços de articulação regional foram sendo organizados, como é o caso da Coordenadora de Centrais Sindicais do Cone Sul (Ccscs). O avanço da participação desses atores de forma articulada e consensual no Mercosul passou a ser um de seus grandes desafios.

Posto isso, o objetivo deste artigo é o de buscar analisar os desafios das centrais sindicais no processo de construção do Mercosul. Interessa a nós compreender como essas organizações vão definindo e construindo estratégias e alianças num espaço regional.

Partimos da seguinte questão: é possível uma articulação regional das centrais sindicais capaz de influenciar o processo de evolução do Mercosul, para garantir ou ampliar os interesses dos trabalhadores por elas representados?

Do ponto de vista metodológico, privilegiamos as percepções dos atores sociais a partir de seus depoimentos. Desta forma, realizamos várias entrevistas, no final de 1998 e início de 1999, com dirigentes das principais centrais sindicais do Brasil e da Argentina. ${ }^{2}$ Utilizamos também documentos publicados por essas centrais, além de estudos realizados por outros pesquisadores.

Dividimos o presente artigo em quatro partes. Na primeira, abordamos os limites e os desafios da participação das centrais sindicais no Mercosul. Partimos de um breve apanhado histórico das centrais, caracterizando a heterogeneidade existente entre elas. A nossa intenção é demonstrar a complexidade da situação em que os sindicatos se articulam. Em seguida, e contrariamente a uma percepção homogeneizadora, verificamos a busca de consenso entre as centrais.

Analisamos o surgimento de estratégias e práticas sindicais transnacionais na terceira parte. Existe um paradoxo entre o diagnóstico dos dirigentes das centrais acerca da globalização e da regionalização e a ação prática de suas organizações com relação ao Mercosul. Isto só pode ser compreendido a partir das motivações das centrais em participar do processo de integração regional e de seus desdobramentos em ações que extrapolam as fronteiras nacionais.

2 As entrevistas foram realizadas nos seguintes momentos: 1) em Brasília, novembro de 1998, durante a reunião do SG 10 do Mercosul; 2) no Rio de Janeiro, dezembro 1998, durante a realização da VII Reunião Plenária do Foro Consultivo Econômico-Social (Fces), por Lúcia Helena Proença Bueno, no âmbito do Projeto de pesquisa "Mercosul, Nafta e Alca: Transnacionalização das Práticas Sindicais", financiado pelo CNPq; 3) em Buenos Aires, abril 1999. 
Posteriormente, nos voltamos às perspectivas de alianças das centrais a partir da caracterização dos principais atores sociais presentes na construção do Mercosul. Por fim, avançamos sobre algumas conclusões deste estudo, mesmo sendo as mesmas em caráter preliminar.

\section{Limites e desafios da participação das centrais sindicais no Mercosul}

Embora haja uma convergência de posicionamento entre as centrais sindicais frente ao Mercosul, como veremos mais adiante, não podemos homogeneizar a participação dessas organizações no processo de integração em curso. Parece-nos oportuno que, ao se colocar o tema deste artigo, devamos fazê-lo tendo em vista a experiência histórica particular das centrais sindicais envolvidas, e buscando compreender a formação de espaços sub-regionais, ou regionais, de interação entre as mesmas.

\section{A heterogeneidade numa perspectiva histórica}

A grande maioria dos países latino-americanos -do pós-guerra até início dos anos 60-, estava sendo governada por partidos e políticos de corte populistanacionalista-desenvolvimentista, que tinham no movimento sindical e na burguesia industrial local para suas principais bases de sustentação (Zapata 1994).

$\mathrm{Na}$ Argentina, o movimento sindical chegou a ter uma maior vinculação político-partidária, participando da própria gerência governamental nos períodos em que o Partido Justicialista (Peronista) esteve no poder. Isto marcará, até os dias de hoje, a posição da mais importante central sindical argentina, a Confederación General del Trabajo (CGT), em sua relação com o governo local, e, conseqüentemente, com o Mercosul.

A partir dos anos 60, os países do Cone Sul passaram a viver sob regimes militares, período em que essa relação entre sindicatos e estado/partidos foi alterada. Os sindicatos passaram a ter um papel menos expressivo no cenário político nacional. Já no início dos anos 80 , intensificaram-se os processos de ajuste e reestruturação econômica nos países da América Latina, indicando fundamentalmente a transição do modelo de desenvolvimento assentado na substituição de importações para o de transnacionalização dos mercados - o que irá afetar sobremaneira a organização dos trabalhadores (Castro 1996: 58). 
Os movimentos sindicais do Brasil, Argentina, Paraguai e Uruguai não só vão tomar rumos distintos durante os governos militares como também vão se conformar de maneira distinta com a redemocratização, encontrando, posteriormente, no Mercosul um espaço privilegiado para uma aproximação.

Diferentemente da experiência da CGT/Argentina (CGT/RA), a Central Única dos Trabalhadores do Brasil (CUT/Br), que surge na primeira metade dos anos 80, tem uma trajetória de oposição aos sucessivos governos locais. Não obstante, essa central tem sido palco de atuação de diferentes tendências. Já antes de sua criação, quando se formou a Comissão Nacional Pró-CUT, em 1981, houve uma série de divergências, intra e extracomissão, que acabaram por cindir o movimento. As principais divergências se relacionavam com as teses da pluridade e liberdade sindical da convenção 87 da Organização Internacional do Trabalho (OIT) e com a realização de uma greve geral, defendida pelo grupo da CUT.

Assim, surge em 1986 a Central Geral dos Trabalhadores (CGT/Br), que vai se distanciar mais ainda da CUT, quando passa a ter uma posição de apoio ao governo da "Nova República". ${ }^{3}$ No final dos anos 80 , os sindicatos ligados ao Partido Comunista do Brasil (PC do B), após perderem a direção da CGT/Br, criaram a Corrente Sindical Classista, aderindo à CUT. À medida que as divergências entre as tendências da CGT se aprofundavam, novas cisões ocorriam, dividindo a CGT em duas: Central Geral dos Trabalhadores -ligada ao Partido Comunista Brasileiro (PCB) e ao Movimento Revolucionário 8 de março (MR-8)-, cujo presidente era Joaquim dos Santos Andrade, e a Confederação Geral dos Trabalhadores, com Rogério Magri na presidência.

Em oposição à vertente socialista da CUT, foi fundada a Força Sindical em 1991, que se apresentava como uma central moderna, independente, apartidária e pluralista. Juntamente com a Confederação Geral dos Trabalhadores, se autodenomina "sindicalismo de resultado". Mais recentemente, observamos a criação de uma nova central no Brasil, de tendência social-democrata: a Social Democracia Sindical (SDS). Esta central busca ocupar um espaço entre as posições mais socialistas da CUT e as tendências mais liberais da Força Sindical. Organizou-se também a Central Autônoma dos Trabalhadores (CAT), cuja origem advém de dissidência da Força Sindical.

3A CGT foi fundada em março de 1986 com o nome de Central Geral dos Trabalhadores, mas em setembro de 1988, em Brasília, um Plenário Nacional decidiu mudar seu nome para Confederação e manter a mesma sigla. O nome de Central, mas com a mesma sigla, será retomado em setembro de 1989 por grupos ligados ao PCB e MR-8 (Costa 1995). 


\section{Desafios, estratégias e alianças das centrais sindicais no Mercosul}

O movimento sindical na Argentina encontra-se dividido, apesar de haver uma certa hegemonia por parte da CGT/RA. Durante o início do primeiro governo do presidente Carlos Menem (1989-1995) a CGT cindiu-se em dois grupos: Azopardo, com Ubaldini à frente, e San Martín, comandada por Güerino Andreoni. O primeiro grupo se colocou em oposição à política oficial, ao tempo em que o segundo acompanhava a gestão do presidente Menem. As divergências se davam em torno das políticas de reforma do Estado e das privatizações, como também de disputas por espaços políticos frente ao Ministério do Trabalho e à condução das "obras sociais".

Em 1992 houve uma reunificação desses dois setores. Todavia, alguns grêmios (principalmente a Associación de Trabajadores del Estado - ATE) reiteraram sua disposição de não integrar a nova CGT por não encontrar uma postura mais crítica com relação à política do governo. Vão constituir o Congreso de Trabajadores Argentinos, que posteriormente transformar-se-á na Central de Trabajadores Argentinos (CTA). Em 1994 houve uma nova cisão na CGT, quando um grupo de sindicatos (caminhoneiros, cervejeiros etc.) formaram o Movimiento de Trabajadores Argentinos (MTA). Além disso, ainda existem no seio da CGT grupos que se opõem em função, principalmente, de sua relação com o governo federal.

Consequiência de um longo período ditatorial, os sindicatos no Paraguai possuem um reduzido poder organizativo, resultando numa menor participação no Mercosul. A partir da Federação dos Bancários, um grupo de sindicatos se articulam em torno do Movimiento Intersindical de Trabajadores (MIT), que em 1989 se transformou na Central Unitaria de Trabajadores (CUT). Além da CUT, cuja trajetória tem sido de oposição aos últimos governos locais, existem no Paraguai duas outras centrais sindicais de origem histórica mais antiga: a Central Paraguaya de Trabajadores (CPT), mais alinhada com a política governamental; e a Central Nacional de Trabajadores (CNT), de oposição moderada.

O movimento sindical uruguaio começou a se rearticular a partir de 1981. Em 1983 houve a formação do Plenario Intersindical de Trabajadores (PIT). Em 1984 o PIT adotou os estatutos da Convención Nacional de Trabajadores (CNT), incorporando a antiga sigla e se apresentando como PIT-CNT. Ao contrário dos outros países da região, a organização sindical no Uruguai é autônoma, com todos os sindicatos vinculados a uma única central, apesar de vigorar a pluridade e a liberdade sindical. 
Por outro lado, a estratégia de pressão do sindicalismo uruguaio é diferente da utilizada pelo outros países do Mercosul, não somente porque a estrutura institucional do governo uruguaio permite a participação do setor sindical nas discussões de temas internos, mas também porque a concentração populacional em Montevidéu, sede do governo, permite ao PIT-CNT uma ampla visibilidade para suas mobilizações e pressões (Pasquariello 1996: 83).

Como podemos observar, existem diferentes tendências sindicais no Mercosul, com distintas origens históricas e culturais, apresentando posicionamentos ideológico, político e partidário que, em alguns casos, se aproximam, mas que, em outros, se opõem frontalmente. Desta forma, podemos nos perguntar: como se dá a articulação entre essas diferentes centrais sindicais? Quais são os seus meios de articulação? Como as centrais estão participando das negociações do Mercosul? E por que estão buscando participar desse processo?

\section{O desafio do consenso}

Mesmo antes da assinatura do Tratado de Assunção (1991) ${ }^{4}$ as centrais sindicais já haviam começado uma articulação sub-regional. Assim, a Coordenadora de Centrais Sindicais do Cone Sul (Ccscs) foi constituída em 1986, objetivando acelerar o restabelecimento da democracia política nos países da região. ${ }^{5}$ Atualmente a Ccscs tem o Mercosul como um espaço privilegiado de atuação, buscando criar condições para o desenvolvimento da "dimensão social" desse processo de integração regional. As principais centrais brasileiras (CUT, CGT e FS) e argentinas (CGT e CTA), a CUT do Paraguai e o PIT-CNT do Uruguai, além da Central Obrera Boliviana (COB) e da Central Unitaria de Trabajadores (CUT) do Chile, fazem parte desta Coordenadora.

Embora em nível nacional as centrais sindicais tenham posições distintas, às vezes, em oposição uma com outra, no âmbito do Mercosul elas conseguem atuar em bloco, de maneira consensual. É notório que a formação do Mercosul possibi-

4 O Tratado de Assunção visa a constituição de um mercado comum entre a Argentina, o Brasil, o Paraguai e o Uruguai.

5 A criação da Cescs contou com o apoio da Confederação Internacional de Organizações Sindicais Livres (Ciols) e de sua representação para o hemisfério americano, a Organização Regional Interamericana de Trabalhadores (Orit). No ano de sua criação, o Paraguai e o Chile ainda estavam sob governos ditatoriais, e nos demais países da sub-região acabava de se produzir a mudança democrática. Para um maior aprofundamento sobre a Ccscs, ler Castillo et alii (1996). 
litou a concretização de uma instância de inter-relacionamento entre as centrais. Diferentemente da situação anterior, em que a discussão se dava sobre os processos de redemocratização, com o Mercosul as organizações sindicais foram levadas a refletir sobre questões que afetam mais diretamente a vida dos trabalhadores, como, por exemplo, os impactos da integração na oferta de emprego, os direitos laborais e leis trabalhistas, o fluxo de mão-de-obra, entre outros.

À medida que as discussões sobre o Mercosul se aprofundavam, a Coordenadora ia apresentando uma nova dinâmica. O surgimento do Mercosul criou condições para revitalizar a Ccscs, já que no período anterior a Coordenadora tinha dificuldades para articular as centrais em ações conjuntas, como nos mostram Castillo et alii (1996), Castro (1996) e Vigevani et Mariano (1999).

Poderíamos analisar esse aprofundamento da inter-relação entre as centrais sindicais a partir da sociologia do conflito de Simmel (1983). Para este autor, o conflito pode ser visto numa ótica positiva, pois é uma forma de se conseguir a unidade. O conflito permite a interação entre os indivíduos; é uma forma de "sociação"; pode até ser um fator de constituição das instituições. Do ponto de vista sociológico, o conflito é produtivo, se guardar um certo limite que permita algum tipo de agregabilidade.

Sendo assim, o Mercosul criou um certo tipo de conflito para as centrais sindicais provocando uma maior interação entre elas, como também entre elas e os governos nacionais, empresários e instituições regionais. No caso específico do movimento sindical, o Mercosul tem sido um importante espaço para o estabelecimento de relações de solidariedade e de desenvolvimento de ações consensuadas, muitas vezes difíceis de serem alcançadas no plano nacional. Vejamos alguns depoimentos de dirigentes sindicais, membros da Ccscs:

Talvez havia mais afinidade entre a CUT/Br e o PIT/CNT/Uruguai do que com a CGT/RA. E somente o fato de termos que trabalhar juntos no Mercosul determinou que podíamos nos agüentar, conviver com conceitos que não são fáceis. Começamos a nos compreender e a verificar que nossas diferenças não eram tão profundas para que não fôssemos amigos, e que podíamos fazer um acordo para brigar contra o inimigo comum. Mesmo se não conseguimos superar todas as nossas diferenças, pelo menos conseguimos minimizá-las em um grau tal que trabalhamos hoje harmonicamente (Enrique Venturini - CGT/RA).

(...) exatamente a gente discute os problemas, a gente discute as propostas, as diversas propostas, as várias visões das centrais sindicais, e através do consenso da participação da Ccscs a gente traça nossas estratégias, nossos objetivos imediatos, a 
médio e a longo prazo, mas dentro de um trabalho limitado onde requer muita participação e especialização (Ruth Monteiro - Força Sindical)

(...) Nós buscamos a unidade de todo o movimento sindical, incluindo os setores que hoje se enfrentam na Argentina. Nós, na Argentina, somos muito diferentes da CGT. Mas não se pode construir uma pressão internacional com parcialidade. (Eduardo Menajosky - CTA)

(...) Nessas reivindicações que eu acabei de manifestar, há um consenso entre todas as centrais sindicais (Kjeld Jakobsen - CUT/Br)

Existe realmente um novo sindicalismo que tem uma dinâmica de política interna própria e que é mais democrático tanto no Brasil (Morais 1997) quanto nos outros países do Mercosul. Progressivamente está sendo construído um maior grau de democracia formal no seio dos sindicatos (Morais 1995), exercendo, sem dúvida, uma influência real e positiva sobre as práticas das centrais sindicais.

Do ponto de vista institucional do Mercosul, as centrais sindicais atuam preferencialmente no Subgrupo 10 (SG 10), chamado Assuntos Trabalhistas, Emprego e Seguridade Social, ${ }^{6}$ e no Foro Consultivo Econômico-Social (Fces). ${ }^{7}$ Todavia, mesmo havendo uma articulação regional, a participação das centrais sindicais nas decisões do Mercosul ainda é bastante limitada.

Primeiramente, existe uma dificuldade de os sindicatos, em termo organizacional, acompanhar com a mesma velocidade as transformações econômicas em curso. A crescente mudança tecnológica, a reestruturação produtiva, as novas técnicas gerenciais das empresas transnacionais, o desemprego e a heterogeneidade dos trabalhadores têm colocado as organizações sindicais numa difícil situação de encontrar novas estratégias para manter o seu poder de influência no mundo atual. ${ }^{8}$

${ }^{6}$ Criado em 1991, mas efetivamente instalado no primeiro semestre de 1992, era denominado de SG-11 até a assinatura do Protocolo de Ouro Preto, em 1994, quando passou a ser chamado de SG-10. Este subgrupo é uma instância tripartite conformada pelos Ministérios do Trabalho dos países do Mercosul, representante dos empregados e dos empregadores, sendo vinculado ao Grupo Mercado Comum (GMC).

${ }^{7}$ O Fces, criado pelo Protocolo de Ouro Preto, é o órgão de representação dos setores econômicos e sociais. Conta com a participação das centrais sindicais, confederações empresariais, organizações de defesa dos consumidores, ONGs, instituições científicas, como por exemplo, no Brasil, a Sociedade Brasileira para o Progresso da Ciência (Sbpc). Apesar de sua representatividade, possui função meramente consultiva. Para um maior conhecimento sobre o tema, consultar Chaloult e Almeida (1999).

${ }^{8}$ A OIT (1997) publicou um relatório dando um panorama do sindicalismo em face dos novos desafios apresentados pelas transformações econômicas mundiais mais recentes. 
No caso específico da integração do Cone Sul, os sindicatos não conseguiram uma maior mobilização dos trabalhadores para alcançar resultados mais significantes em suas reivindicações. A opinião pública foi pouco sensibilizada para essas questões. ${ }^{9}$ Existe, portanto, uma incapacidade de as organizações sindicais influenciarem, de forma mais profunda, as negociações do Mercosul e de criarem uma agenda própria que possam garantir um maior protagonismo desses atores. Como defende Pasquariello (1996), a atuação e a estratégia do sindicalismo pautaram-se na própria ação do estado. Isto quer dizer que os parâmetros usados pelas centrais para definir suas opções e políticas foram as decisões tomadas pelos governos.

Um outro aspecto a ser considerado deriva dos poucos espaços de participação direta da sociedade criados no âmbito do Mercosul. Os executivos "controlam" totalmente a regionalização em curso, existindo um déficit democrático decorrente do limitado espaço reservado à participação dos sindicatos e de outros atores sociais, como organizações não-governamentais $(\mathrm{ONG})$, movimentos sociais, universidades e diversas entidades da sociedade civil. Mesmo os poderes legislativos desenvolvem um papel de tão-somente ratificar os acordos assinados pelos governos, como foi o caso do Protocolo de Ouro Preto ${ }^{10}$ (Chaloult 1997).

$\mathrm{Na}$ estrutura do Mercosul, as instâncias de decisão pertencem todas aos poderes executivos, ao passo que a Comissão Parlamentar Conjunta (CPC), o Fces e o SG-10 têm apenas caráter consultivo. ${ }^{11}$ Entretanto, poderíamos questionar: não estaria a sociedade representada nas negociações do Mercosul através dos poderes executivos eleitos democraticamente?

Não se trata aqui exclusivamente de uma questão de representação, mas, dentro de uma concepção "habermasiana" de democracia, de possibilitar espaços onde se possa exigir uma argumentação capaz de colocar em xeque o Estado, para que o mesmo não funcione com a sua própria lógica. Conseqüentemente, podemos dizer que ainda é bastante limitado o espaço público de discussão sobre o Mercosul. Prevalece a lógica do Estado, liderada pelos poderes executivos dos países membros, mesmo havendo coalizões políticas em torno dele.

${ }^{9}$ No Uruguai há uma maior discussão por parte da sociedade decorrente da dimensão e localização daquele país, e, conseqüentemente, dos possíveis impactos que a integração regional poderia lhe causar.

${ }^{10}$ Assinado em dezembro 1994 pelos quatro presidentes do Bloco, completou o arcabouço do Mercosul, permitindo-lhe constituir uma personalidade jurídica própria.

${ }^{11}$ De acordo com o que consta no artigo 26 do Protocolo de Ouro Preto, a CPC, criada pelo artigo 24 do Tratado de Assunção, pode somente fazer recomendações às instâncias deliberativas do Mercosul (Conselho do Mercado Comum - CMC, através do GMC). 
No entanto, os sindicatos têm ampliado seu espaço de participação a partir de novas estratégias e de novas práticas. Estas, por sua vez, resultam do esforço pela busca do consenso, da conciliação e da negociação flexível, em face da diversidade das centrais. Como nos sugere Rodrigues (1996: 341-342), analisando a situação da CUT/Br, "o movimento sindical terá que adotar uma postura mais afirmativa, negociando à exaustão cada ponto que considere problemático aos interesses dos trabalhadores (...) esse é um dos grandes desafios que os sindicatos terão que enfrentar para continuarem mantendo a adesão de seus representados neste final de século".

\section{Estratégias e práticas sindicais transnacionais}

\section{Globalização e regionalização: o diagnóstico das centrais sindicais}

As centrais sindicais apresentam um diagnóstico extremamente negativo da globalização, que pode ser percebido em suas publicações ou nos depoimentos de seus dirigentes. São unânimes em afirmar que a globalização econômica causou impacto profundo no mundo do trabalho, provocando desemprego, exclusão, perdas salariais, concentração de renda, deterioração dos direitos coletivos de trabalho, flexibilização das relações laborais e crise sindical.

(...) A globalização vem acompanhada de um modelo neoliberal, que tem uma reestruturação forte, uma desregulação de direitos em nome dessa globalização que precariza trabalhos e isso impacta negativamente, pois você tem uma perda da representação sindical e um forte processo de instabilidade interna, dentro do chamado mundo do trabalho (Rafael Neto - CUT/Br)

(...) A globalização impactou de forma profunda no seio do conjunto de trabalhadores na Argentina, porque significou a deterioração de todas as condições de trabalho, a baixa salarial, a perda dos direitos consagrados dos convênios coletivos e a perda da estabilidade do trabalho. Hoje, há milhões de trabalhadores argentinos desocupados, ou subocupados, precários, os quais não têm nenhuma organização sindical que os representem, e que, definitivamente, são reféns do sistema (Victor Mendibil - CTA)

Por outro lado, podemos constatar uma relação ambígua das centrais sindicais com o processo de regionalização. Está claro para os representantes sindicais que a formação do Mercosul tem privilegiado, exclusivamente, as relações econômicas e comerciais, deixando à margem suas preocupações sociais. Acreditam também 


\section{Desafios, estratégias e alianças das centrais sindicais no Mercosul}

que, assim como a globalização econômica, a regionalização tem servido para atender os grandes interesses das empresas transnacionais. ${ }^{12}$ Para os dirigentes das centrais sindicais, o Mercosul, até o presente, pouco contribuiu para a melhoria das condições de vida dos trabalhadores; talvez tenha mesmo, em alguns casos onde a concorrência interna levou à falência de algumas empresas, prejudicado a vida de seus representados. No entanto, as centrais têm como postura defender o Mercosul, participar de sua construção e buscar intervir neste processo, mesmo reconhecendo os seus limites.

O Mercosul tem muito futuro na medida em que seja realmente um processo de integração, que não seja somente um mercado aduaneiro e financeiro, senão que seja um processo de integração com vocação política, que tenha realmente um processo de democratização (...) É interesse dos trabalhadores defender o Mercosul, defender a dimensão social do Mercosul (...) Como conseguir que os trabalhadores, a sociedade civil participe mais do Mercosul? Nós dissemos que para a crise do Mercosul, mais Mercosul (Carlos Custer - CTA).

(...) esperamos que o Mercosul possa ser um processo mais democrático, com uma participação maior das diversas sociedades que estão sendo afetadas pelo Mercosul (...) A prioridade da CUT frente ao Mercosul é a garantia que o Mercosul não se mantenha meramente em um acordo comercial, que beneficie somente grandes empresas, mas que pudesse ser um acordo de integração complementar, ou seja, o Brasil vendendo para a Argentina aquilo que nós temos e que eles não têm e viceversa, de modo a gerar mais produção, mais emprego (Kjeld Jakobsen - CUT/Br).

Após essas considerações, podemos indagar: por que as centrais sindicais buscam participar desse processo, mesmo avaliando que no Mercosul pouco se avançou nas questões sociais?

\section{A estratégia da participação}

Existe uma constatação para a maior parte dos dirigentes sindicais entrevistados: independentemente da participação das centrais, o Mercosul continuaria existindo e se desenvolvendo.

(...) logo, como nós sabemos, essa globalização, e mesmo o Mercosul, são coisas inevitáveis (Vicentinho - CUT/Br).

${ }^{12}$ Este tipo de argumentação também é muitas vezes formulado pelos líderes de alguns partidos comunistas ou ex-comunistas da Europa em relação à construção da União Européia. 
Nós estamos participando do processo de integração, primeiramente, porque ele vai se desenvolver independentemente da participação da CGT. O mundo avança para uma economia mais integrada (Francisco Gutierez - CGT/RA).

Todavia, as centrais sindicais, em face de um Estado que cada vez menos intervém nas economias nacionais, começam a ver no Mercosul uma possibilidade de se criar estruturas capazes de proteger os trabalhadores das fortes transformações provocadas pela globalização, conforme diagnosticam seus dirigentes. O Mercosul é um processo de integração de jure, onde o Estado desempenha um papel fundamental (Oman 1994). ${ }^{13}$ Embora em nível nacional o Estado tenha buscado limitar sua intervenção nas regulações econômicas, no plano regional é o Estado dos países membros, através de seus governos e de suas burocracias, quem lidera o processo de integração.

Quando no Tratado de Assunção definiu-se que o Mercosul deveria avançar em direção a um mercado comum, houve uma mudança na atitude sindical, estimulada pela ação do Estado. Os sindicatos se colocavam numa posição defensiva, pois viam no Mercosul uma ameaça de perda de direitos conquistados, seja pela abertura comercial, seja pelos riscos de desregulamentação do mercado de trabalho, seja pela possibilidade de homogeneização desses direitos pelos níveis mais baixos entre os quatro países. A integração era sinônimo de liberalização comercial e econômica.

Mas, ao mesmo tempo que aprofundavam a participação das organizações dos trabalhadores nas negociações do Mercosul, e os governos absorviam essa participação com a criação do Subgrupo de Trabalho 11, as centrais sindicais passaram a ter uma atitude mais propositiva.

Para Vigevani e Veiga (1996), as percepções, atitudes e motivações que conduzem à participação sindical propositiva no Mercosul foram, sobretudo, o resultado de avaliações mais ou menos orgânicas e sistemáticas, de quais os rumos que o processo de integração regional estava tomando e de quais conseqüências traria para os trabalhadores. A estratégia das centrais, especialmente da CUT/Br, apoiava-se na idéia de que, embora a condução do Mercosul refletisse a hegemonia da doutrina neoliberal na América Latina, o movimento sindical poderia intervir dispu-

${ }^{13}$ Segundo Oman, a regionalização pode ser de facto ou de jure. É de facto quando se dá uma intensa integração natural entre países fronteiriços, como tem sido o caso do Canadá e dos Estados Unidos durante as últimas décadas. Já a integração de jure ocorre quando, por meio de arranjos políticos e institucionais, dois ou mais países de uma região formam um bloco econômico, como por exemplo a União Européia e o Mercosul. 
tando com o governo e setores empresariais a conformação do processo de integração, que não estava muito bem definida (Vigevani 1998).

Desta forma, assim como os Estados, os sindicatos participam do Mercosul a partir de uma lógica que busca ampliar seus espaços políticos de negociação em nível nacional, através das negociações em âmbito regional. As centrais sindicais vislumbram no Mercosul uma oportunidade de garantir e negociar direitos sociais, os quais, em âmbito nacional, estão cada vez mais sendo pressionados pelas transformações econômicas em curso. Logo, as centrais utilizam a integração regional como instrumento para fortalecer suas próprias posições nos diferentes contextos nacionais.

Desde o início a nossa posição foi de não combater o processo, mas de participar dele para influir, para podermos garantir os direitos dos trabalhadores e a finalidade de que seria o desenvolvimento econômico regional (...) (Ruth Monteiro - Força Sindical).

A nossa luta no movimento sindical é no sentido de assegurar que a gente globalize as conquistas, globalize nossa solidariedade, respeitando a cultura de cada país, que melhore o salário mínimo para todos, que tenha uma carga social, que acabe com o trabalho escravo, com o trabalho infantil, que garanta direitos e que a gente faça comparações entre um país e outro, se aquele país paga um salário melhor, todo mundo tem que se igualar, se as condições de saúde do outro é melhor, tem que se igualar (Vicentinho-CUT/Br).

As nossas motivações em participar estão relacionadas com a compreensão do fato que, num contexto da globalização, o único marco que permite construir instrumentos de compensação sobre os seus efeitos negativos, em termos econômicos e sociais, é a existência de um espaço regional ampliado (Claudio Lozano - CTA).

\section{Práticas sindicais transnacionais}

As centrais sindicais estão se articulando, principalmente, em dois níveis: 1) em nível do conjunto das centrais, através da Ccscs; 2) em nível setorial ou bilateral, por meio da aproximação entre sindicatos, confederações ou centrais de dois ou mais países.

O primeiro nível de articulação, pela sua própria natureza, tem tratado de temas mais gerais vinculados aos interesses do conjunto das centrais no Mercosul. Seu espaço privilegiado de atuação é o SG-10 e o Fces. Inicialmente as demandas sindicais se estruturaram em torno da Carta de Direitos Fundamentais para o 
Mercosul, em que as centrais buscavam a construção de um sistema de regras laborais e sociais que garantissem iguais direitos e condições de trabalho para todos os trabalhadores.

Inspirada nas convenções da OIT, esta Carta fazia parte da estratégia das centrais em criar espaços sociais no Mercosul e garantir sua "dimensão social". Por recomendação do SG-10, o Grupo Mercado Comum (GMC) aprovou 34 convenções da OIT, sendo que 11 foram ratificadas pelos países membros. Todavia, os dirigentes sindicais avaliam que o resultado prático da ratificação dessas convenções foi praticamente inexistente, pois sua instrumentalização e operacionalização dependiam de fatores internos a cada país. ${ }^{14}$

(...) a Carta de Direitos Fundamentais deveria estar clara quanto às convenções da OIT que os quatro países deveriam ratificar. A realidade é que chegamos em dezembro de 1994 e conseguimos aprovar no Subgrupo 34 convenções que vão além do que tínhamos na Carta. $\mathrm{O}$ fato é que os governos não internalizaram essas decisões e nunca as aprovaram (...) (Enrique Venturini - CGT/RA).

Através de diversas cartas dirigidas aos presidentes dos quatro países, manifestações conjuntas, atos públicos, as organizações sindicais fizeram críticas quanto ao modelo de integração implementado e buscaram ampliar seu espaço de participação. ${ }^{15}$ Como resultado foi criado o Fces.

Durante o período de 1991 a 1994 (...) a única coisa que conseguimos foi receber uma resposta a nossas críticas quanto à forma como avançava o Mercado Comum, exclusivamente sob a base do comercial e do econômico, com exclusão total das questões sociais e laborais. Digo que nos deram uma resposta, pobre, mas uma resposta: os governos aceitaram no Protocolo de Ouro Preto, em dezembro de 1994, a criação do Foro Consultivo Econômico-Social do Mercosul como uma instituição (Enrique Venturini - CGT/RA).

${ }^{14} \mathrm{Na}$ Argentina a ratificação não garante a sua operacionalização imediata, necessitando de norma jurídica interna. No caso brasileiro, ao contrário do que ocorre no Uruguai, inexiste uma cultura sindical que tenha como referência os princípios e os direitos que encerram esses instrumentos normativos da OIT (CUT 1997).

${ }^{15}$ No período de 1992 a 1995, as principais centrais sindicais do Mercosul endereçaram cinco cartas formais aos presidentes dos quatro países. Por outro lado, paralelamente às reuniões ordinárias dos presidentes dos países membros do Mercosul, ou durante as reuniões ampliadas, como é o caso da Alca, as centrais organizam manifestações públicas. Da mesma forma, tem se tornado comum a realização de ato conjunto no dia $1^{\circ}$ de maio; em 1999, o ato foi na fronteira do Brasil com o Uruguai, em Rivera-Santana do Livramento. 
Diferentemente dos subgrupos (SG-10, por exemplo) que compõem a estrutura do GMC, o Fces é um dos seis órgãos da estrutura do Mercosul. Devido ao fato de que em seu regulamento as decisões devem ser aprovadas por consenso, as centrais têm tido dificuldades para fazer avançar suas proposições. Os interesses sindicais geralmente são distintos dos interesses empresariais, havendo a necessidade de negociação, o que leva a alterações de suas propostas originais.

(...) cada vez que queremos lograr iniciativas sobre o tema social e laboral, os empresários, se não é um é outro, se opõem sempre. E o que aprovamos é tão debilitado que às vezes indagamos se foi ou não proveitoso (Enrique Venturini CGT/RA).

O processo de conformação do Fces, como também a retomada das discussões no então recém-criado SG-10, possibilitaram um novo impulso à participação das centrais após o Protocolo de Ouro Preto. Antes, houve um período de uma certa animosidade sindical.

Na nova agenda apresentada ao SG-10, a demanda pela Carta Social permanece. No entanto, segundo Castro (1996: 69), ela passa a ter um novo significado: "Passa a estar mais vinculada à necessidade de estabelecimento de um espaço social no Mercosul do que a uma espécie de trincheira contra o rebaixamento dos patamares laborais na região".

Através da Coordenadora as centrais vão se articular tanto no SG-10 quanto no Fces para elaborar a Declaração Sociolaboral do Mercosul. Em dezembro de 1998, esta Declaração foi aprovada pelos presidentes dos estados partes, mas com caráter promocional, e não sancionador, com aspecto vinculante, conforme propunham as centrais.

Quando a Coordenadora apresentou a proposta de adoção de um protocolo sociolaboral, com efeito vinculante e dotado de uma Comissão de Seguimento e Aplicação, tinha duas metas prioritárias a serem atingidas: 1) estabelecer um conjunto de direitos que os quatro países estariam obrigados a cumprir e respeitar, elevando assim o patamar básico de direitos sociais com uma regulação laboral adequada à nova situação de União Aduaneira; 2) criar um espaço em nível institucional permitindo a apresentação de queixas e de denúncias de conflitos trabalhistas, para onde a pressão sindical pudesse se dirigir no enfrentamento dos problemas sociais e laborais no Mercosul (CUT 1999).

Apesar de considerar que a Declaração aprovada é insuficiente, devido ao seu formato e caráter, a CUT/Br avalia que a segunda meta da Coordenadora foi 
alcançada na medida em que se criou a Comissão Sociolaboral do Mercosul, primeiro órgão tripartite auxiliar do GMC. ${ }^{16} \mathrm{O}$ objetivo desta Comissão é de fomentar e acompanhar a aplicação da Declaração Sociolaboral do Mercosul. Constituiu-se, portanto, um espaço para o tratamento e negociação dos temas sociais e laborais, cujas sugestões serão remetidas diretamente ao GMC, principal órgão executivo do Mercosul.

Assim, as centrais têm logrado ampliar seus espaços de participação no Mercosul, embora seus dirigentes considerem que foram poucos os avanços alcançados até o momento. Nesse nível de articulação, através de ações consensuais do conjunto das centrais em torno da Ccscs, não é possível progredir em negociações mais específicas, devido ao seu caráter generalizante. Todavia, os sindicatos estão também se articulando por setor, ou por empresa, o que possibilita o aprofundamento das práticas sindicais transnacionais.

(...) a construção regional tem um nível que é coletivo e que pertence à esfera regional, mas existem muitas ações que devemos desenvolver no âmbito das relações bilaterais (Eduardo Menajosky - CTA).

Nesse segundo nível de articulação os sindicatos atuam dentro das estruturas institucionais do Mercosul, como também fora delas - no âmbito das empresas transnacionais, por exemplo. No primeiro caso, mesmo sendo o SG-10 o grupo de maior participação, as centrais sindicais (principalmente a CUT/Br e a CGT/RA) têm estado presentes nos subgrupos de atividades específicas, como o de Indústria, Agricultura, Meio Ambiente, Energia, Transporte e Infra-estrutura.

Em muitos casos os sindicatos estão articulados pelos Secretariados Profissionais Internacionais (SPIs), que agrupam os trabalhadores por setor de atividade em nível internacional, regional ou subregional. ${ }^{17}$ Através da realização de vários seminários, os SPIs têm tratado temas específicos com as organizações sindicais afiliadas dos países do Mercosul: bancário, automotriz, energia elétrica, alimenta-

${ }^{16}$ Criada no dia 9 de março de 1999, na 33ª reunião do GMC, em Assunção.

${ }^{17}$ Até 1996 existiam doze SPIs operando na América Latina e no Caribe: Federação Internacional dos Trabalhadores das Indústrias Metalúrgicas (Fitim); Internacional de Pessoal de Serviço de Correios, Telégrafos e Telefone (Ipctt); Federação Internacional de Trabalhadores da Indústria Têxtil, de Vestuário e Couro (Fitivc); União Internacional de Trabalhadores da Alimentação e Afins (Uita; integrou-se na Fitpas), Federação Internacional de Sindicatos de Trabalhadores da Indústria Química, Energia e Indústrias Diversas (Icef; integrou-se na Federação Internacional de Mineiro - Icem) e outras. 
ção e outras (Castillo et alii 1996). Os sindicalistas do setor siderúrgico do Mercosul, por exemplo, fizeram dois encontros, organizados pela Comissão Sindical dos Metalúrgicos do Mercosul, em que intercambiaram informações sobre o setor e articularam sua participação nas reuniões do SG Indústria. Os resultados das negociações dentro dos subgrupos ainda são pouco expressivos, mas existe um ganho qualitativo na participação dos representantes sindicais nessas instâncias.

Além do mais, existe uma tendência de os sindicatos buscar em negociações por empresa, ou por grupo empresarial. Para Castro (1999), isto se deve à crescente descentralização negocial das empresas que operam na região, dificultando as negociações centralizadas, ou seja, por ramo de atividade.

Como conseqüência desta nova atitude, ocorreu, em abril de 1999, um fato inédito no Mercosul: foi assinado, entre duas fábricas de uma empresa, o primeiro contrato coletivo "que estabelece os princípios básicos de relacionamento entre capital e trabalho no âmbito do Mercosul" (Contrato Coletivo 1999). A iniciativa foi da Volkswagen do Brasil e da Argentina, envolvendo, no Brasil, o Sindicato dos Metalúrgicos do ABC e o Sindicato dos Trabalhadores nas Indústrias e Oficinas Metalúrgicas, Mecânicas e de Material Elétrico e Eletrônico, Siderúrgicas e Automobilísticas e de Autopeças de Taubaté, Tremembé e Distritos, assim como a Confederação Nacional dos Metalúrgicos da CUT; na República Argentina, assinou o Sindicato de Mecânicos e Afins de Transporte Automotor.

Nesse contrato as partes consideram a necessidade de se estender os entendimentos das relações capital e trabalho no âmbito do Mercosul, de estreitar a comunicação e troca de informações entre as mesmas e de ampliar o diálogo para um melhor conhecimento e entendimento das realidades e peculiaridades da $\mathrm{Ar}$ gentina e do Brasil. Consideram também a potencialidade do Mercosul e a estratégia da empresa frente à concorrência. A obtenção de melhores índices de produtividade, qualidade, e outros, deve ser discutida e analisada entre as partes (Contrato Coletivo 1999).

Existe neste caso, portanto, uma convergência entre a estratégia da empresa, que busca ampliar sua inserção no Mercosul, através da melhoria do padrão de qualidade de seus produtos, como também da produção articulada entre suas duas fábricas; e a estratégia dos sindicatos, que visam aumentar seu poder de negociação a partir de um contrato coletivo bilateral em âmbito regional. Possivelmente, 
essa iniciativa, cuja possibilidade de êxito será maior quanto mais integrado for o setor, deverá ser seguida por outras empresas e sindicatos. ${ }^{18}$

Podemos dizer, enfim, que as centrais sindicais optaram por uma estratégia de negociação flexível no Mercosul, em detrimento de uma estratégia de confronto ou simplesmente de crítica. O Mercosul instrumentaliza a flexibilização das negociações. Os espaços de participação das centrais são instâncias tripartites, cujas decisões são tomadas somente por consenso. Isto exige uma atitude de maior flexibilidade. Não é pelo fato de a Declaração Sociolaboral ter sido aprovada no SG10 sem caráter vinculante, devido à posição dos empresários, que as centrais se retirariam das negociações. Apesar da avaliação de que a Declaração ficou parcialmente esvaziada, as organizações sindicais permaneceram buscando aprofundar as negociações.

Essas mudanças refletem também uma situação das centrais em nível nacional. A CUT/Br, por exemplo, de tradição "confrontacionista", tem adotado uma postura de maior negociação em nível local, mesmo sendo criticada por algumas das tendências que a compõem.

Verificamos essa tendência em alguns estudos realizados no Brasil, como o de Arbix (1996), onde o autor estima que no começo dos anos 90 as novas condições produtivas e políticas da economia aberta de um regime democrático exigiam mudanças nas táticas e estratégias do movimento sindical, havendo maior ênfase na negociação. Mangabeira (1993) e Oliveira (1994) defendem também a tese de que o movimento sindical deve caminhar na trilha da tentativa de conciliação. Isto não quer dizer, no entanto, que se tenha excluído o conflito. É um padrão de ação sindical muitas vezes baseado na cooperação conflitiva (Colbari 1997).

Outro aspecto que deve ser ressaltado é o de que as centrais também estão saindo do nível das declarações e entrando em negociações mais específicas.

Não somente uma nova postura estratégica e uma nova agenda estão se desenvolvendo dentro desse processo de integração, mas também que os sindicatos

${ }^{18}$ Em abril de 1998, os trabalhadores do Grupo Gerdau - incluindo, além de brasileiros e uruguaios, chilenos e canadenses-, reuniram-se, por iniciativa da Confederação Nacional dos Metalúrgicos (CNM-CUT) e do Steelworkers do Canadá, objetivando, entre outras coisas, estabelecer uma meta para se chegar a uma negociação coletiva em nível continental. Da mesma forma, trabalhadores da Scania do Brasil e da Argentina, articulados pela CNM-CUT e Smata, iniciaram, no final de 1997, conversações que poderão levar ao estabelecimento de um contrato coletivo (Castro 1999). 
começam a transformar suas estruturas e a perceber a necessidade de qualificar seus quadros para potencializar suas ações em âmbito regional. Por fim, os sindicatos começam a refletir sobre a necessidade de estabelecer novas alianças.

(...) essas mudanças estão relacionadas com o processo de integração regional. Houve mudanças nas agendas de discussão dos sindicatos sobre os temas internacionais (...) provocando um efeito maior que seria na reestruturação interna das organizações sindicais, como, por exemplo, organizando, ampliando ou revalorizando o papel da secretaria de relações internacionais, que antes era uma questão meramente formal. Os dirigentes que estão hoje nesses lugares são os mais importantes (...) (Pablo Topet - CGT/RA).

\section{As perspectivas de alianças das centrais}

O Mercosul está estimulando discussões sobre as possibilidades de alianças entre os atores sociais. À medida que cresce a consciência dos impactos da integração regional -positivos ou negativos-, os atores da sociedade civil exigem maior transparência e participação nos processos decisórios. O resultado disso pode se dar com o aumento da capacidade de negociação desses atores, concretizando-se através de alianças no plano nacional ou através de articulações em âmbito internacional. Esses atores buscam, desta forma, uma atuação de protagonistas na construção do Mercosul. Caracterizaremos a seguir, sumariamente, os principais atores sociais envolvidos na integração do Cone Sul, para posteriormente apontarmos algumas perspectivas de alianças das centrais sindicais.

Mônica Hirst (1996) identifica dois tipos de atores no Mercosul: os de primeiro e os de segundo nível. Trata-se de uma diferenciação no grau de participação, determinado por condicionantes econômicos e políticos e pelo formato institucional do próprio processo associativo. No primeiro nível estão a burocracia, os grupos empresariais e as principais lideranças políticas; no segundo, situam-se os partidos políticos, as organizações sindicais e outras organizações como as ONGs.

Assim, existe um corpo de funcionários governamentais nos Ministérios de Relações Exteriores e nas agências econômicas especializadas de cada país que conduz o processo de integração. Suas ações dependem da aprovação de seus respectivos governos, aos quais devem prestar contas sobre o resultado de cada negociação.

Devemos diferenciar o segmento empresarial entre a atuação das empresas transnacionais, os grandes grupos nacionais, os médios e pequenos empresários e os produtores rurais. São distintos atores, com diferentes poderes de pressão no 
Mercosul, em defesa de seus interesses. Fazendo uso da categorização de Hirst, poderíamos dizer que somente os dois primeiros atores se enquadrariam no primeiro nível.

Já as principais lideranças políticas envolvidas limitam-se praticamente aos presidentes dos quatro países. A vontade presidencial transformou-se num elemento central nas negociações do Mercosul. Essa, por sua vez, não se identifica com programas partidários. ${ }^{19}$ Os partidos políticos, assim como os parlamentares, possuem uma participação limitada e/ou desarticulada em torno da agenda integracionista.

Outrossim, destacamos também as organizações internacionais como importantes atores nos processos de integração. Algumas como a Organização dos Estados Americanos (OEA), o Banco Interamericano de Desenvolvimento (BID), a Comissão Econômica para a América Latina e o Caribe (CEPAL) das Nações Unidas e a Organização Pan-Americana de Saúde (Opas) desenvolvem um importante papel na elaboração e implementação de novos acordos regionais, além de possibilitar um certo apoio logístico na execução dos mesmos (Chaloult 1999).

Portanto, é no meio desse mosaico de atores sociais que devemos analisar as perspectivas de alianças das centrais sindicais. Vimos, anteriormente, que os sindicatos estão construindo uma aliança sub-regional, regional e mesmo internacional entre si, para fazer frente às transformações no mundo do trabalho. No caso específico do Mercosul, ela se concretiza dentro da Coordenadora e de outras organizações setoriais. Esta é a aliança prioritária das centrais e a que mais se tem aprofundado.

Todavia, é perceptível a dificuldade de as organizações sindicais ampliar suas alianças com outros atores. Não existe uma estratégia plenamente elaborada das centrais, nem mesmo da Ccscs, para estabelecer alianças fora do escopo sindical. Talvez pela própria evolução histórica do Mercosul, ou pela tradição sindical hegemônica, ${ }^{20}$ os dirigentes sindicais têm uma percepção pouco positiva de alian-

${ }^{19}$ No caso uruguaio houve uma mobilização significante dos partidos e dos parlamentares na etapa inicial do Mercosul. No Brasil e na Argentina não se observa a incorporação (ou quando há é periférica) desse tema nos programas dos partidos políticos. No Brasil, especificamente, são sobretudo os representantes políticos dos estados do Sul que têm se interessado pelo processo de integração, devido, entre outros motivos, aos impactos na agricultura da região.

${ }^{20}$ A CUT/Br tem uma certa liderança no meio das demais centrais nas negociações do Mercosul. Isto se deve a sua estrutura, representatividade e qualidade de seus quadros. Ela possui o maior número de publicações sobre o tema, como também é a central que mais tem promovido seminários, treinamentos, encontros etc. para capacitar seus quadros. 
ças com alguns setores governamentais e com os grandes grupos empresariais, sem descartar sua possibilidade.

É importante destacar que existe uma aproximação das posições defendidas pela CUT/Br com as defendidas pelo PIT-CNT do Uruguai, pela CTA da Argentina e pela CUT do Paraguai, o que acaba por influenciar, sobremaneira, a posição do conjunto das centrais em nível da Coordenadora.

As perspectivas das centrais é de ampliar suas alianças junto aos setores nãogovernamentais, como também aos de micro, pequenos e médios empresários nacionais, cuja situação frente à integração possa estar próxima à dos trabalhadores.

Hoje temos que fazer não uma frente sindical, mas uma frente social que seja capaz de ter poder suficiente para negociar com os grandes setores econômicos e com os governos reivindicações sobre a qualidade de vida no Mercosul. Se não conseguirmos esta frente social, sem dúvida que o desempenho do Mercosul vai passar pelo centro de decisão das multinacionais, em conivência com as burocracias ou as tecnoburocracias dos governos; e que, certamente, não vão defender os interesses dos povos, senão os interesses do capital financeiro internacional (Ramon Ermacora - CGT/RA).

(...) nós temos absolutamente claro que se não tiver uma pressão dos trabalhadores em relação aos organismos governamentais do Mercosul, não vamos conseguir nada que estamos reivindicando. Então, as estratégias se dão nesses três pontos: uma articulação regional do movimento sindical, a participação institucional e a pressão sindical (Rafael Neto - CUT/Br).

Devemos considerar também que a criação do Fces possibilitou às centrais um novo espaço para o estabelecimento de alianças. Sendo uma instância eminentemente de representação da sociedade civil, as centrais têm encontrado uma situação favorável para aglutinar novos aliados. Suas propostas, discutidas previamente no seio da Coordenadora, são incorporadas por outros atores no Fces. Diferente do SG-10, o Fces possibilita a participação de diversos atores em nível regional, como também em nível nacional. ${ }^{21}$ Esta é uma boa perspectiva para as centrais ampliarem sua alianças em nível local.

${ }^{21}$ Isto se deve ao formato do Fces, que se constitui em Seções Nacionais dos Estados Partes do Mercosul, com autonomia para definir os setores econômicos e sociais que as compõem. Cada Seção Nacional tem direito a nove delegados titulares no Plenário do Foro, o que garante seu caráter regional. A Coordenação Administrativa do Plenário do Foro é exercida pelo período de seis meses, em sistema de rodízio, pela Seção Nacional do Estado Parte que estiver exercendo a presidência do Conselho do Mercado Comum do Mercosul. 
Finalmente, a relação entre as centrais e os governos, além do que já consideramos, possui um forte componente nacional. Na Argentina a CGT/RA fez parte da base de apoio do presidente Menem, enquanto a CTA se aproxima de uma aliança de oposição a este governo. Da mesma forma, a CUT é oposição ao governo de Fernando Henrique Cardoso, ao tempo que a Força Sindical e a CGT/Br lhe prestam um certo apoio. Embora os governos nacionais tenham restringido a participação das organizações sindicais no Mercosul, eles não desejam que os sindicatos deixem de participar. O Mercosul necessita de uma base de sustentação social para ter maior legitimidade. Os governos querem que os sindicatos se envolvam na construção do Mercosul, contribuindo para legitimar o processo como um todo. Entretanto, esse envolvimento deve ter limitações. Dessa forma, mesmo havendo uma correlação de força desfavorável para as centrais, os governos cedem em algumas de suas reivindicações. Assim, podemos considerar que as centrais sindicais e os governos são, pois, aliados potenciais numa perspectiva estratégica maior de consolidação e desenvolvimento do Mercosul.

\section{Conclusão}

É possível perceber que as centrais sindicais estão construindo uma articulação regional no âmbito do Mercosul. Seja através da Coordenadora de Centrais Sindicais do Cone Sul, das Secretarias Profissionais Internacionais, de Confederações Sindicais, ou de acordos bilaterais entre sindicatos ou centrais sindicais, as organizações dos trabalhadores estão estabelecendo relações solidárias transnacionais.

Ao mesmo tempo que o Mercosul aparece como uma ameaça às conquistas dos trabalhadores, ele também é percebido como uma possibilidade de proteção e de ampliação de direitos laborais em face das transformações econômicas mundiais. As centrais sindicais possuem, assim, uma relação ambígua com o processo de integração regional.

Uma das principais estratégias das centrais no Mercosul é criar espaços políticos de negociação em nível nacional, através de negociações regionais. Isto decorre, entre outros, do novo papel do Estado nacional, que intervém cada vez menos nos processos econômicos locais, especialmente no que se refere às relações laborais. Esta situação não se coloca em âmbito regional, tendo em vista que o Mercosul é um processo de integração de jure, em que o Estado, através do poder executivo e da burocracia, é o seu principal ator social. Desta forma, desenvolvem- 
se espaços regionais tripartites de negociação, cuja possibilidade de existência em nível nacional tem sido praticamente descartada pelos Estados. São novos espaços de discussão entre governo, empresários e trabalhadores.

Sendo assim, as centrais sindicais optaram por uma estratégia de negociação flexível em detrimento do confronto ou simplesmente da crítica. A estrutura institucional do Mercosul propicia o desenvolvimento de uma maior necessidade de negociação por parte das centrais, haja vista que todas as decisões, sejam no Subgrupo 10 ou no Foro Consultivo Econômico-Social, devem ser tomadas por consenso.

Por outro lado, articuladas pela Ccscs, as centrais buscam ampliar seus espaços de participação para garantir um maior protagonismo na conformação do Mercosul, tendo uma postura mais afirmativa como indica os estudos de Rodrigues (1996). Embora constatamos que os dirigentes das centrais consideram que os avanços obtidos até agora foram limitados, é notório que, do ponto de vista político, as organizações sindicais avançaram sobremaneira.

Os últimos dez anos permitiram a trabalhadores de distintos países, antes vivendo num certo isolamento, aproximar-se e dar os primeiros passos para a construção de relações de confiança e o desenvolvimento de uma linguagem comum. Foi o resultado de várias ações no âmbito da Ccscs, SPIs, SG-10 e Fces. Essa construção compartilhada é um fato sindical inédito na região, que poderá ser a base para uma cultura sindical supranacional. Devemos compreender esta situação como parte integrante de um sistema de valores políticos, sociais e morais comuns, apesar de toda a heterogeneidade existente entre as centrais sindicais. A aliança que se estabeleceu entre as centrais do Cone Sul precisa agora ganhar corpo fora do espectro sindical e chegar a outros setores interessados em aprofundar os aspectos que vão além do comercial, fortalecendo assim a "dimensão social" do Mercosul, objetivo maior das centrais sindicais.

\section{Referências bibliográficas}

Arbix, Glauco (1996). Uma aposta no futuro. São Paulo: Scritta.

Castro, Maria Silvia Portella de (1999). Negociações coletivas internacionais e Mercosul. In: Yves Chaloult e Paulo Roberto de Almeida. Mercosul, Nafta e Alca: a dimensão social. São Paulo: LTr, p. 191-216. (1996). A estratégia da ação sindical no Mercosul. Revista Brasileira de

Política Internacional. 2(39): 72-93. 
Castillo, Geraldo, et al. (1996). Los trabajadores y el Mercosul. Creación, desarrollo y políticas sindicales de la Coordinadora de Centrales Sindicales del Cone Sur (Ccscs). Buenos Aires: Corregidor.

Chaloult, Yves e Paulo Roberto de Almeida (1999). Mercosul, Nafta e Alca: A dimensão social. São Paulo: LTr.

Chaloult, Yves (1999). Relações Mercosul, Alcsa, Alca e papel do Estado. In: Yves Chaloult e Paulo Roberto de Almeida. Mercosul, Nafta e Alca: A dimensão social. São Paulo: LTr, p. 38-68.

(1997). Transnacionalização das práticas sindicais no Mercosul. Política Comparada. 1(1,1): 173-185.

Colbari, Antônio (1997). Confronto e negociação na ação sindical dos portuários capixabas: as determinações do contexto sócio-econômico regional. Trabalho apresentado no VIII Congresso da SBS, Brasília, 7-9 ago.

Contrato Coletivo (1999). Contrato assinado entre a Volkswagen do Brasil e da Argentina e sindicatos do setor automobilístico desses países, São Bernardo do Campo, abr.

Costa, Sílvio (1995). Tendência e Centrais Sindicais. O movimento sindical brasileiro de 1978 a 1994. Goiânia: Anita Garibaldi, 287 p.

CUT (Central Única dos Trabalhadores) (1999). Boletim Mercosul. Florianópolis, 6, fev.

(1997). Para formação da rede nacional de formação da CUT. Caderno sobre o Mercosul. Florianópolis, nov., 76 p.

Hirst, Mônica (1996). A dimensão política no Mercosul: atores, politização e ideologia. In: Hélio Zylbertajn et al. Processo de integração regional e a sociedade: o sindicalismo na Argentina, Brasil, México e Venezuela. Rio de Janeiro: Paz e Terra, p. 272-308.

Mangabeira, Wilma (1993). Dilemas do novo sindicalismo. Rio de Janeiro: RelumeDumará/ANPOCS.

Morais, Jorge Ventura de (1997). Dinámica de la política interna del nuevo sindicalismo brasileño. Revista Mexicana de Sociología. México, 1(59): 205227. fev.-mar.

(1995). Novo sindicalismo e democracia sindical: um teste e uma crítica do modelo eleitoral. Dados. 3 (38): 545-579.

OIT (Organização Internacional do Trabalho) (1997). El trabajo en el mundo 199798: Relaciones laborales, democracia y cohesión social. Genebra, 299 p. 
Oliveira, Marco Antônio de (1994). Avanços e limites do sindicalismo brasileiro recente. In: Carlos Alonso Barbosa de Oliveira et al. (orgs.). $O$ mundo do trabalho. São Paulo: Página Aberta, p. 497-518.

Oman, Charles (1994). Globalisation et régionalisation: quels enjeux pour les pays en développement? Paris: Ocde.

Pasquariello, Karina Lilia (1996). Mercosul e sindicatos: a participação das centrais sindicais no subgrupo 11. São Paulo, 147 p. Dissertação (mestrado). USP.

Rodrigues, Iram Jácome (1996). Os dilemas da CUT. Sociedade e Estado, 2 (11): 321-344. jul.-dez.

Simmel, Georg (1983). A natureza sociológica do conflito. In: Evaristo de Morais Filho (org.). Sociologia. Textos de Simmel. São Paulo: Ática, p. 123-134.

Vigevani, Tullo, Karina Pasquariello Mariano (1999). Estratégias e alianças entre os atores sociais. In: Yves Chaloult e Paulo Roberto de Almeida. Mercosul, Nafta e Alca: A dimensão social. São Paulo: LTr, p. 97-119.

Vigevani, Tullo (1998). Mercosul: impactos para trabalhadores e sindicatos. São Paulo: LTr.

Vigevani, Tullo e João Paulo Veiga (1996). Mercosul: interesse e mobilização sindical. In: Hélio Zylbertajn et al. Processos de integração regional e a sociedade: o sindicalismo na Argentina, Brasil, México e Venezuela. Rio de Janeiro: Paz e Terra, p. 223-248.

Zapata, Francisco (1994). Crise do sindicalismo na América Latina. Dados. Rio de Janeiro.

Zylbertajn, Hélio et al. (orgs.) (1996). Processos de integração regional e a sociedade: o sindicalismo na Argentina, Brasil, México e Venezuela. Rio de Janeiro: Paz e Terra, 381p.

\section{Entrevistas Realizadas:}

Vicente Paula da Silva (Vicentinho) - Presidente da CUT/Br

Kjeld A. Jakobsen - Secretário de Relações Internacionais da CUT/Br

Rafael Freire Neto - Diretor Executivo da CUT/Br

Ruth Monteiro - Dirigente da Força Sindical

Armando Gonçalves - Representante da Força Sindical no SG10

Valdir Vicente de Barros - Secretário de Relações Internacionais da CGT/Br

Oscar Enrique Venturini - Diretor do Departamento de Assuntos Internacionais da CGT/RA; representante na Ccscs, SG 10 e Fces 


\section{Civitas - Revista de Ciências Sociais}

Ano 1, $n^{o} 1$, outubro 2000

Pablo Topet - Representante da CGT/RA no SG 10

Francisco Gutierez - Secretário de Assuntos Internacionais da CGT/RA

Luisa Mele - Representante da CGT/RA no SG 10

Oscar Remorini - Representante da CGT/RA no SG 10

Luis Anzaldo - Representante da CGT/RA no SG 10 - e Julio Gerardi (Assessor)

José Antônio Arajuo - Representante da CGT/RA no SG 10

Juan José Rodriguez - Representante da CGT/RA no SG 06

Carlos Irrera - Secretário de Regionais Nacional do Sindicato dos bancários -e Eduardo Berrozpe (Secretário de imprenssa de Buenos Aires) - CGT/RA

Ramon Ermacora - CGT/RA - INCASUR

Suzana Santomingo -Assessora da Secretaria de Assuntos Internacionais / Federação Argentina de Empregados de Serviço e Comércio - e Eduardo San Román (assessor) - CGT/RA

Victor Mendibil - Secretário Gremial da CTA

Carlos Custer - CTA / Incasur / Membro da Ccscs

Claudio Lozano - Diretor do Instituto de Investigação da CTA - representante no Fces e Ccscs

Eduardo Menajosky - Diretor do Departamento Internacional da CTA / representante no Fces e Ccscs

Marcelo Bustos Fierro - CTA

Brasília, setembro de 1999 